\title{
ANALYTICAL MODELS FOR ESTIMATION OF THE MAXIMUM STRAIN OF BEAM STRUCTURES BASED ON OPTICAL FIBER BRAGG GRATING SENSORS
}

\author{
Se Woon CHOI ${ }^{\mathrm{a}}$, Jihoon $\mathrm{LEE}^{\mathrm{b}}$, Byung Kwan $\mathrm{OH}^{\mathrm{b}}$, Hyo Seon PARK ${ }^{\mathrm{b}}$ \\ ${ }^{a}$ Department of Architecture, Catholic University of Daegu, 712-702 Gyeongsan, South Korea \\ ${ }^{b}$ Department of Architectural Engineering, Yonsei University, 120-749 Seoul, South Korea
}

Received 10 Jan 2013; accepted 26 Mar 2013

\begin{abstract}
The structural safety of a beam structure is assessed by a comparison between the maximum stress measured during monitoring and the allowable stress of the beam. However, the strain directly measured from a fiber Bragg grating (FBG) strain sensor may not be identical with the actual maximum strain induced in the structural member. Unless a FBG strain sensor is installed exactly on where maximum strain occurs, the reliability of the evaluated safety based on the measured strain depends on the number and location of sensors. Therefore, in this paper, analytical models are presented for estimation of the maximum values of strains in a linear elastic beam using the local strains measured from FBG sensors. The model is tested in an experiment by comparing estimated maximum strain from FBG sensors and directly measured strain from electrical gages. For the assessment of safety of typical beam structures in buildings and infrastructures, analytical models for various loading and boundary conditions are provided.
\end{abstract}

Keywords: fiber optic sensor, strain sensing, health monitoring, FBG strain sensor, steel beams.

\section{Introduction}

Maximum stress in a structural member for buildings and infrastructures can exceed an allowable stress when the structure is subjected to various loads such as earthquake, wind, or unexpected loads. Additionally, structural members in complex-shaped buildings can experience unexpected overloads or stresses due to the complexity of architectural configurations (Keras et al. 2005; Scott et al. 2007). If a member is subjected to a higher stress than the allowable stress, the safety and serviceability of the member should be checked to prevent unexpected damages. For this reason, strain-based structural health monitoring (SHM), the maximum stress in a structural member has been widely used as clear index to assess the state of the member (AISC 1989; Farrar, Worden 2007).

Since the actual stress distribution induced in a beam structure by varying amounts and types of loads is non-uniform, the strain directly measured from a strain sensor is not identical with the actual maximum strain induced in the structural member. Unless a strain sensor is installed exactly on where maximum strain occurs, the reliability of the evaluated safety based on the measured strain depends on the number and location of sensors. Therefore, to reduce the number of sensors, the average strains from long gauge fiber optic sensors (LGFOS) or vibrating wire strain sensors (VWSGs) have been used in estimating the maximum strain, since LGFOS or VWSGs measure integrated strain over a relatively long gauge length (Park et al. 2005, 2007; Lee, Park 2011).

Although point sensors measure local strain, fiber Bragg grating (FBG) strain sensors can successfully overcome the limitation on the gage length by a multiplexing technology (Grattan, Sun 2000; Li et al. 2004; Majumder et al. 2008). The multiplexing is a method by which multiple signals are combined into one signal, and hence it makes only single cable suffice for the multiple sensors. In addition, FBG sensors are easy to install and increase the number of sensors compared to long gauge sensors including LGFOSs and VWSGs. For these reasons, FBG strain sensors have been widely applied in various fields even though a FBG sensor measures strain at a local point.

Therefore, in this paper, analytical models are presented for the determination of the maximum values of strains or stresses in a beam structure based on the local strain measured from FBG sensors. The models define the relation between measured local strains and maximum strains for various types of loading and boundary conditions for linear elastic beam structures in buildings or infrastructures. The model is tested in an experiment by comparing estimated maximum strain from FBG sensors and directly measured strain from electrical gages.

Corresponding author: Hyo Seon Park

E-mail: hspark@yonsei.ac.kr 


\section{FBG strain sensors}

The FBG sensor utilizes Bragg grating technology. A Bragg grating can be understood as an optical fiber with a periodic refractive index perturbation pattern inscribed in the core such that it diffracts the optical signal in the guided mode at specific wavelengths into other corebounded modes provided the index period is of the order of the interrogation wavelength (López-Higuera et al. 2011; Delepine-Lesoille et al. 2008). If the broadband light source collide against the Bragg grating, a light with particular wavelength, called as Bragg wavelength $\left(\lambda_{B}\right)$, satisfying the relationship shown in Eqn (1) is reflected. This principle is illustrated in Figure 1 and the relation of Bragg grating and Bragg wavelength is given by:

$$
\lambda_{B}=2 n_{\text {eff }} \Lambda,
$$

where: $\Lambda$ is the period of Bragg grating; $n_{\text {eff }}$ is effective refractive index. Based on the fact that Bragg grating varies according to changes of temperature, $\Delta T$, pressure, $\Delta P$, and elongation, $\Delta L$, strain can be calculated by detecting the change of Bragg wavelength:

$$
\frac{\Delta \lambda_{B}}{\lambda_{B}}=a \Delta T+b \frac{\Delta L}{L}+c \Delta P,
$$

where: $a, b$ and $c$ are constant coefficients with $\mathrm{a} \approx 8 \times 10^{-6}{ }^{\circ} \mathrm{C}, \mathrm{b} \approx 0.8 \times 10^{-6} \mu \mathrm{m}^{-1}$ and $\mathrm{c} \approx 3 \times 10^{-6} \mathrm{MPa}^{-1}$, respectively.

As the beam structure deforms, either by expansion or contraction, FBG sensor bonded or embedded into the structure elongates or contracts accordingly. Then, strain due to the elongation or contraction induced in an FBG can be measured by the relative change of Bragg wave length in Eqn (2). A wide range of applications of FBG strain sensors can be found in the field of structural health monitoring of buildings, bridges, and civil structures (Méndez 2007).

\section{Analytical model}

Analytical model is presented to estimate the maximum strain of a linear elastic beam structure by defining the relation between the local strains measured from FBG and the maximum strain. Seven types of typical beam structures subjected to various loading conditions are considered in this study.

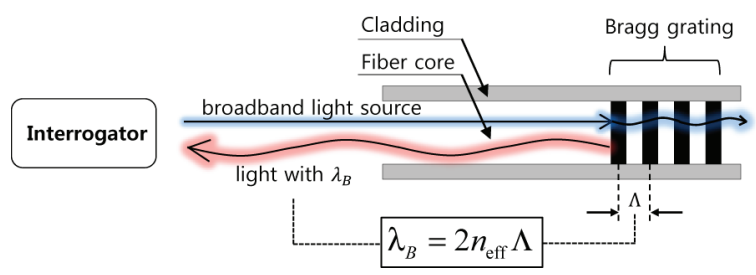

Fig. 1. Principle of fiber Bragg grating

\subsection{Simply supported beams subjected to uniformly distributed load}

For a simply supported beam subjected to the uniformly distributed load with magnitude of $\omega$, as in Figure 2, the longitudinal strain of the beam, $\varepsilon(x)$, is expressed as a function of the distance $x$ from the left-hand support:

$$
\varepsilon(x)=\frac{1}{E Z}\left(\frac{\omega L}{2} x-\frac{\omega}{2} x^{2}\right),
$$

where: $E$ is the modulus of elasticity; $Z$ is the elastic section modulus; $L$ is the length of the beam and $x$ is distance from left-hand support. If the FBG sensor is installed at the distance of $x_{F B G}$ from the left-hand support for the measurement of local strain, as in Figure 2, the measured strain from the FBG sensor $\varepsilon_{F B G}$ is given by:

$$
\varepsilon_{F B G}=\frac{1}{E Z}\left(\frac{\omega L}{2} x_{F B G}-\frac{\omega}{2} x_{F B G}^{2}\right) .
$$

From Eqn (4), the distributed load $\omega$ can be expressed by:

$$
\omega=\frac{2 E Z \varepsilon_{F B G}}{x_{F B G}\left(L-x_{F B G}\right)} .
$$

By substituting $\omega$ in Eqn (5) into Eqn (3), longitudinal strain at arbitrary point can be expressed by:

$$
\varepsilon(x)=\frac{x^{2}-L x}{x_{F B G}\left(x_{F B G}-L\right)} \omega_{F B G .} .
$$

Then, the location of the maximum strain in the beam structure can be found by taking derivative of Eqn (6) with respect to and setting to zero:

$$
\frac{\partial \varepsilon(x)}{\partial x}=\frac{2 x-L}{x_{F B G}\left(x_{F B G}-L\right)} \varepsilon_{F B G}=0 .
$$

Therefore, using the location for the maximum strain from Eqn (7), the analytical model that defines the relationship between the maximum strain $\varepsilon_{\max }$ and the measured local strain from $\mathrm{FBG} \varepsilon_{F B G}$ is given by:

$$
\varepsilon_{\max }=\frac{L^{2}}{4 x_{F B G}\left(L-x_{F B G}\right)} \varepsilon_{F B G} .
$$

Regardless of the location of the FBG sensor, the maximum stress in the simply supported beam structure

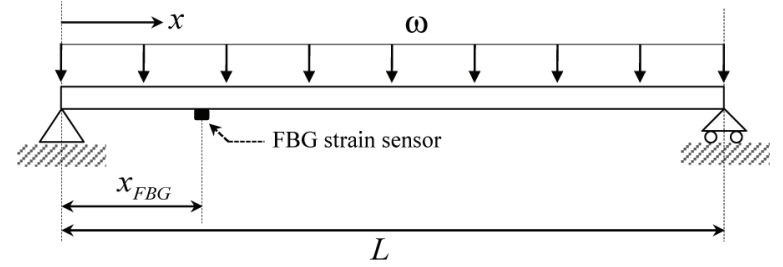

Fig. 2. Simply supported beam subjected to uniformly distributed load 
subjected to the distributed load of $\omega$ can be estimated by Eqn (8).

\subsection{Simply supported beams subjected to a concentrated load}

For a simple-supported beam, as in Figure 3, the concentrated load $P$ acts at the arbitrary distance $a$ from the lefthand support and distance $b$ from the right-hand support. Based on general concepts in engineering mechanics, the longitudinal strain of the beam, $\varepsilon(x)$, can be expressed as a function of the distance $x$ from the left-hand support:

$$
\varepsilon(x)=\left\{\begin{array}{ll}
\frac{P b}{E Z} x & (0 \leq x \leq a) \\
\frac{P a}{E Z}(L-x) & (a \leq x \leq L)
\end{array} .\right.
$$

If the FBG sensor is installed at the distance of $x_{F B G}$ from the left-hand support for the measurement of local strain, as Figure 3, the measured strain from the FBG sensor $\varepsilon_{F B G}$ is given by:

$$
\varepsilon_{F B G}=\left\{\begin{array}{ll}
\frac{P b}{E Z} x_{F B G} & 0 \leq x_{F B G} \leq a \\
\frac{P a}{E Z}\left(L-x_{F B G}\right) & a \leq x_{F B G} \leq L
\end{array} .\right.
$$

From Eqn (10), the concentrated load $P$ can be expressed by:

$$
P=\left\{\begin{array}{ll}
\frac{E Z}{b x_{F B G}} \varepsilon_{F B G} & 0<x_{F B G} \leq a \\
\frac{E Z}{a\left(L-x_{F B G}\right)} \varepsilon_{F B G} & a \leq x_{F B G}<L
\end{array} .\right.
$$

By substituting $P$ in Eqn (11) into Eqn (9), longitudinal strain at arbitrary point can be expressed by:

$$
\varepsilon(x)=\left\{\begin{array}{ll}
\left\{\begin{array}{ll}
\frac{x}{x_{F B G}} \varepsilon_{F B G} & 0<x_{F B G} \leq a \\
\frac{b x}{a\left(L-x_{F B G}\right)} \varepsilon_{F B G} & a \leq x_{F B G}<L
\end{array}(0 \leq x \leq a)\right. \\
\left\{\begin{array}{ll}
\frac{a(L-x)}{b x_{F B G}} \varepsilon_{F B G} & 0<x_{F B G} \leq a \\
\frac{L-x}{L-x_{F B G}} \varepsilon_{F B G} & a \leq x_{F B G}<L
\end{array}(a \leq x \leq L)\right.
\end{array} .\right.
$$

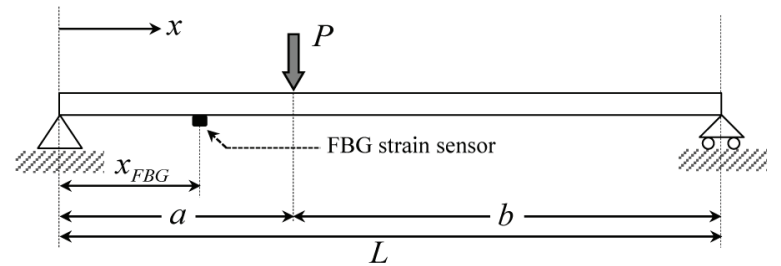

Fig. 3. Simply supported beam subjected to concentrated load
In the case of the beam subjected to a concentrated load, the maximum strain occurs at the point where the load is applied. Then, the analytical model that defines the relationship between the maximum strain $\varepsilon_{\max }$ and the measured local strain from $\mathrm{FBG} \varepsilon_{F B G}$ is given by:

$$
\varepsilon_{\text {max }}=\left\{\begin{array}{ll}
\frac{a}{x_{F B G}} \varepsilon_{F B G} & 0<x_{F B G} \leq a \\
\frac{b}{L-x_{F B G}} \varepsilon_{F B G} & a \leq x_{F B G}<L
\end{array} .\right.
$$

Therefore, regardless of the location of the FBG sensor, the maximum stress in the simply supported beam structure subjected to the point load $P$ can be estimated by Eqn (13).

\subsection{Analytical models for beams}

Determining the maximum values of stresses in beam structures is essential in assessing the safety of beams. To estimate the maximum stresses with a minimized number of FBG sensors, the relationships between the maximum and local strains are established in the previous sections. Based on the relationships, the analytical model is derived to estimate the maximum strain using the local strains measured from FBG sensors. The analytical models can be given in the general form:

$$
\varepsilon_{\max }=\beta \times \varepsilon_{F B G} .
$$

To provide convenient access to the relationships, the values of $\beta$ for typical beam structures subjected to various loading conditions are given in Tables 1 and 2 .

\section{Test of the model}

To verify the performance of the analytical model, a bending test of the simply supported steel beam subjected to a concentrated load was conducted. The schematic diagram of the test model is shown in Figure 4. A concentrate load was applied at the midpoint of the steel beam of $\mathrm{H}-100 \times 100 \times 6 \times 8$ section with the length of $4000 \mathrm{~mm}$. The concentrated load was increased in three steps: $4.8 \mathrm{kN}, 8 \mathrm{kN}$, and $11.2 \mathrm{kN}$. As shown in Figure 4, measurements during static testing were performed with both 7 FBG sensors and 7 electrical strain gauges (ESGs) attached at the surface of the bottom flange of the steel beam with equal intervals of $500 \mathrm{~mm}$. The gage lengths of FBG strain sensors and ESGs used in this study were $10 \mathrm{~mm}$ and $5 \mathrm{~mm}$, respectively.

When the concentrated load is applied by means of a hydraulic jack as shown in Figure 5, the beam deflects downward and the maximum tensile strain occurs at the midpoint. Using the measured strains from both 7 FBGs and 7 ESGs, the distributions of strains along the length of the beam are shown in Figure 6. In Table 3, the maximum strain directly measured from the ESG at the midpoint is compared with the estimated maximum 
Table 1. Values of $\beta$ for the beams subjected to distributed load

\begin{tabular}{|c|c|c|}
\hline Loading condition & $\begin{array}{l}\text { Condition of FBG } \\
\text { sensor location }\end{array}$ & $\beta$ value $\left(\beta=\varepsilon_{\text {max }} / \varepsilon_{F B G}\right)$ \\
\hline 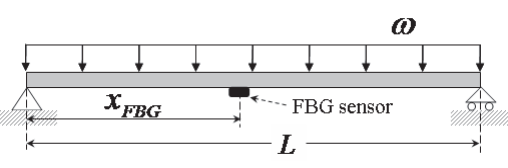 & $0<x_{F B G}<L$ & $\beta=\frac{L^{2}}{4 x_{F B G}\left(L-x_{F B G}\right)}$ \\
\hline 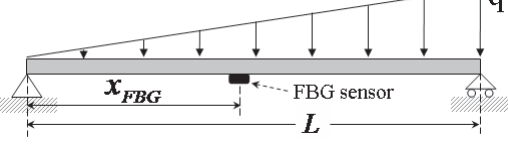 & $0<x_{F B G}<L$ & $\beta=\frac{2 \sqrt{3} L^{3}}{9 x_{F B G}\left(L^{2}-x_{F B G}^{2}\right)}$ \\
\hline 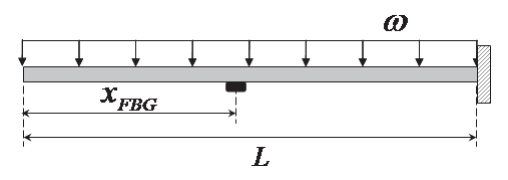 & $0<x_{F B G} \leq L$ & $\beta=\frac{L^{2}}{x_{F B G}^{2}}$ \\
\hline 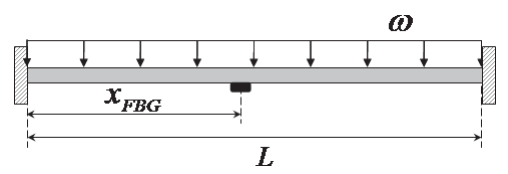 & $\begin{array}{l}0 \leq x_{F B G} \leq L \\
x_{F B G} \neq 0.211 L \\
x_{F B G} \neq 0.789 L\end{array}$ & $\beta=\frac{-L^{2}}{2\left(L^{2}-6 L x_{F B G}+6 x_{F B G}^{2}\right)}$ \\
\hline
\end{tabular}

Table 2. Values of $\beta$ for the beams subjected to concentrated load

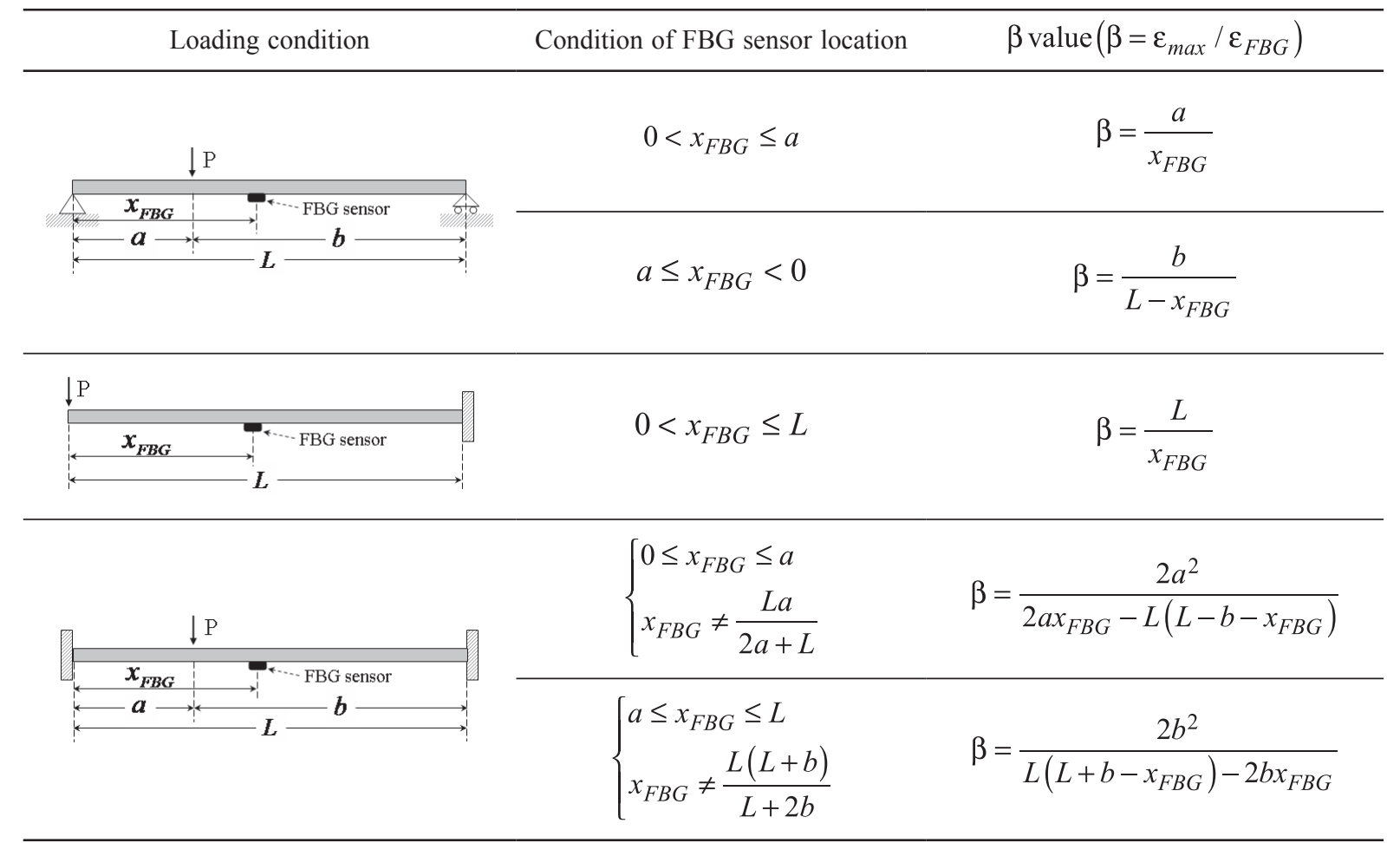


strains based on the analytical model in Eqn (14). For each loading step, the maximum strains can be estimated by 7 measured strains from 7 FBGs located at different locations as shown in Figure 4. The maximum differences are found to be less than $2.6 \%$ for each load step. The

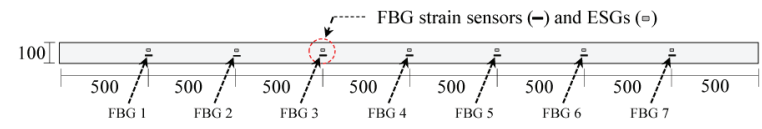

(a) Bottom view

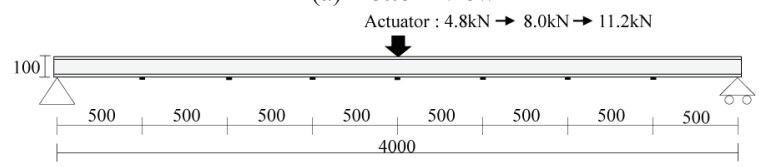

(b) Side view

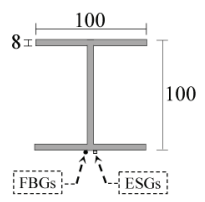

(c) Section

Fig. 4. Experimental setup for test model (unit: $\mathrm{mm}$ )

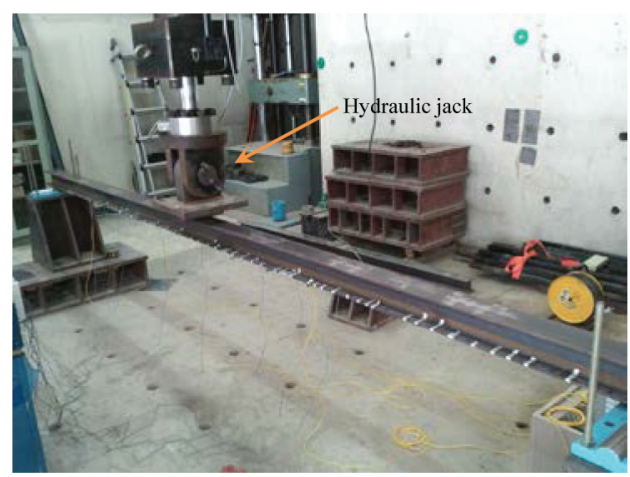

Fig. 5. Simply supported beam and hydraulic jack results indicate a good agreement between the measured and estimated strains. Figure 7 shows a comparison between the estimated maximum strains obtained through the analytical model and the maximum strain measured directly by electrical strain gauge.

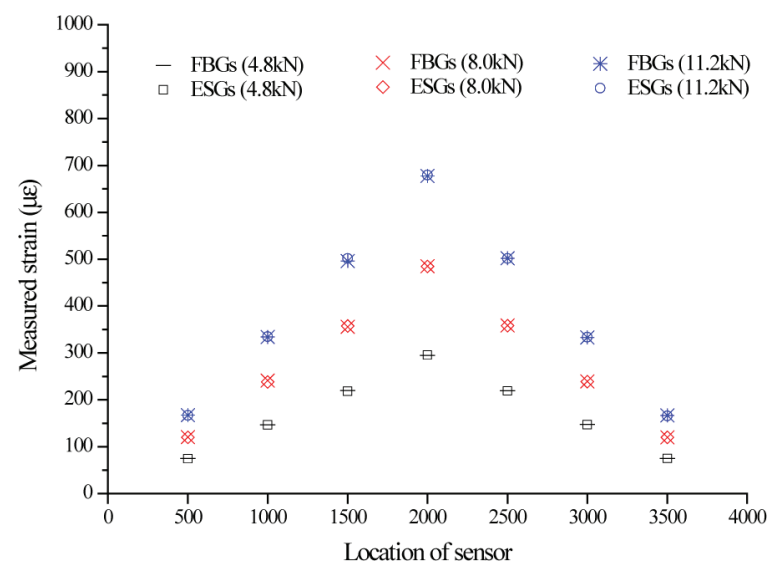

Fig. 6. Measured strains by both of 7 FBG sensors and 7 ESGs

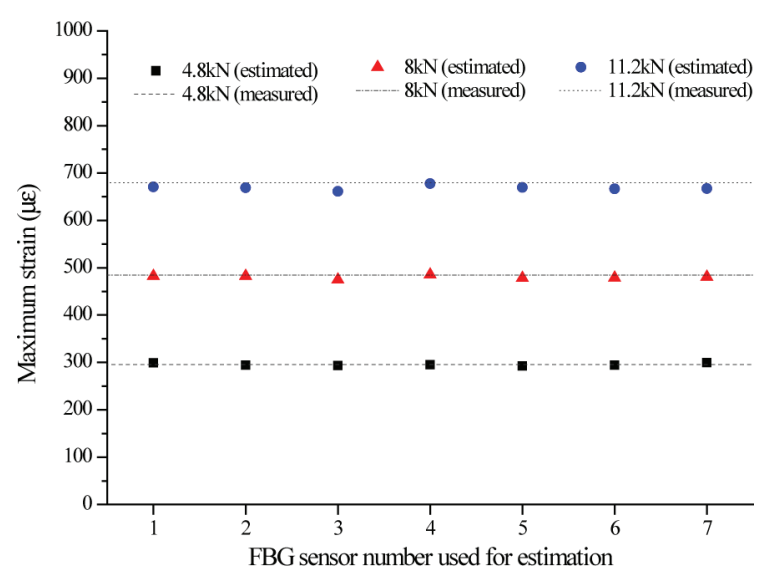

Fig. 7. Comparison between maximum strains estimated by analytical model using FBG sensor and direct measured

Table 3. Comparison of the maximum strains between estimation and measurement

\begin{tabular}{|c|c|c|c|c|c|c|c|c|}
\hline \multirow{3}{*}{$\begin{array}{l}\text { Loading } \\
\text { step }\end{array}$} & \multirow{3}{*}{$\begin{array}{c}\text { Maximum strain } \\
\text { directly measured } \\
\text { by ESG }(\mu \varepsilon)\end{array}$} & \multicolumn{7}{|c|}{$\begin{array}{l}\text { Estimated maximum strain by analytical model using a FBG sensor }(\mu e) \\
\text { (Relative error of estimation to the measurement }(\%))\end{array}$} \\
\hline & & \multicolumn{7}{|c|}{ FBG sensor located on: } \\
\hline & & $500 \mathrm{~mm}$ & $1000 \mathrm{~mm}$ & $1500 \mathrm{~mm}$ & $2000 \mathrm{~mm}$ & $2500 \mathrm{~mm}$ & $3000 \mathrm{~mm}$ & $3500 \mathrm{~mm}$ \\
\hline \multirow{2}{*}{$\begin{array}{l}\text { step } 1 \\
(4.8 \mathrm{kN})\end{array}$} & & 299.3 & 294.3 & 293.4 & 294.7 & 292.8 & 294.4 & 299.7 \\
\hline & 295.7 & (1.2) & $(0.5)$ & $(0.8)$ & $(0.3)$ & $(1.0)$ & $(0.5)$ & (1.4) \\
\hline \multirow{2}{*}{$\begin{array}{l}\text { step } 2 \\
(8.0 \mathrm{kN})\end{array}$} & & 482.1 & 482.0 & 474.7 & 485.2 & 478.1 & 478.5 & 480.5 \\
\hline & 484.5 & $(0.5)$ & $(0.5)$ & $(2.0)$ & $(0.2)$ & $(1.3)$ & $(1.2)$ & $(0.8)$ \\
\hline \multirow{2}{*}{$\begin{array}{l}\text { step } 3 \\
(11.2 \mathrm{kN})\end{array}$} & & 670.5 & 668.7 & 661.5 & 677.5 & 669.2 & 666.3 & 667.2 \\
\hline & 679.2 & (1.3) & (1.5) & (2.6) & $(0.2)$ & (1.5) & (1.9) & (1.8) \\
\hline
\end{tabular}




\section{Conclusions}

In this paper, analytical models to estimate the maximum strains of linear elastic beam structures subjected to various loading conditions are presented. The models are derived by defining the relationship between the maximum strain induced in a beam structure and the measured local strain from a FBG attached at an arbitrary location. The estimation model was tested in an experiment by comparing the maximum strains measured directly from ESGs and the estimated maximum strains based on local strains from FBG strain sensors. The maximum values of strains estimated from the analytical model agreed quite well with the directly measured values from electrical strain gauges. For the assessment of safety of a beam in buildings and infrastructures, analytical models for beam structures with typical boundary conditions subjected to various loadings are provided. For more practical applications, the values of $\beta$ in Eqn (14) need to be derived according to boundary and loading conditions.

\section{Acknowledgements}

This work was supported by the National Research Foundation of Korea (NRF) grant funded by the Korea government (MEST) (No. 2011-0018360).

\section{References}

AISC. 1989. Allowable stress design. American Institute of Steel Construction, Illinois.

Delepine-Lesoille, S.; Merliot, E.; Gautier, Y. 2008. Optical fiber strain sensors for use in civil engineering: state-of-the-art, industrial applications and outlook, BLPC 272: 123-140.

Farrar, C. R.; Worden, K. 2007. An introduction to structural health monitoring, Philosophical Transactions of the Royal Society A 365(1851): 303-315. http://dx.doi.org/10.1098/rsta.2006.1928

Grattan, K. T. V.; Sun, T. 2000. Fiber optic sensors technology: an overview, Sensors and Actuators A: Physical 82(1-3): 40-61. http://dx.doi.org/10.1016/S0924-4247(99)00368-4
Keras, V.; Valys, A.; Mockiene, J. 2005. Stress-strain concentrations in high-rise structure elements and monotonic disintegration under the influence of environment contamination, Journal of Civil Engineering and Management 11(1): 49-55.

http://dx.doi.org/10.1080/13923730.2005.9636332

Lee, H. M.; Park, H. S. 2011. Measurement of maximum strain of steel beam structures based on average strains from vibrating wire strain gages, Experimental Techniques 37(2): 23-29.

http://dx.doi.org/10.1111/j.1747-1567.2011.00733.x

Li, H. N.; Li, D. S.; Song, G. B. 2004. Recent application of fiber optic sensors to health monitoring in civil engineering, Engineering Structures 26(11): 1647-1657. http://dx.doi.org/10.1016/j.engstruct.2004.05.018

López-Higuera, J. M.; Cobo, L. R.; Incera, A. Q.; Cobo, A. 2011. Fiber optic sensors in structural health monitoring, Journal of Lightwave Technology 29(4): 587-608. http://dx.doi.org/10.1109/JLT.2011.2106479

Majumder, M.; Gangopadhyay, T. K.; Chakraborty, A. K.; Dasgupta, K.; Bhattacharya, D. K. 2008. Fibre Bragg gratings in structural health monitoring - present status and applications, Sensors and Actuators A: Physical 147(1): 150-164. http://dx.doi.org/10.1016/j.sna.2008.04.008

Méndez, A. 2007. Fiber Bragg grating sensors: a market overview, in Proceedings of SPIE, Third European Workshop on Optic Fibre Sensors, 4-6 July 2007, Napoli, Italy, 6619. $6 \mathrm{p}$.

http://dx.doi.org/10.1117/12.738334

Park, H. S.; Jung, H. S.; Kwon, Y. H.; Seo, J. H. 2005. Mathematical models for assessment of the safety of steel beams based on average strains from long gage optic sensors, Sensors and Actuators A: Physical 125(2): 109-113. http://dx.doi.org/10.1016/j.sna.2005.04.038

Park, H. S.; Jung, S. M.; Lee, H. M.; Kwon, Y. H.; Seo, J. H. 2007. Analytical models for assessment of the safety of multi-span steel beams based on average strains from long gage optic sensors, Sensors and Actuators A: Physical 137(1): 6-12. http://dx.doi.org/10.1016/j.sna.2007.01.015

Scott, D.; Farnsworth, D.; Jackson, M.; Clark, M. 2007. The effects of complex geometry on tall towers, The Structural Design of Tall and Special Buildings 16(4): 441-455. http://dx.doi.org/10.1002/tal.428

Se Woon CHOI. Assistant Professor at the Department of Architecture, Catholic University of Daegu, South Korea. He received his $\mathrm{PhD}$ degree in Architectural Engineering from Yonsei University. His main research interest is the design of large-scale structures and structural optimization.

Jihoon LEE. MSc Student at the Department of Architectural Engineering, Yonsei University, South Korea. He received his BS degree in Architectural Engineering from Yonsei University. His main research interest is structural health monitoring.

Byung Kwan OH. PhD Student at the Department of Architectural Engineering, Yonsei University, South Korea. He received his MS degree in Architectural Engineering from Yonsei University. His main research interest is the structural monitoring and structural optimization.

Hyo Seon PARK. Professor at the Department of Architectural Engineering, Yonsei University, South Korea. He received his PhD degree in Civil Engineering from The Ohio State University. His main research interest is the design of high-rise buildings, structural optimization, structural health monitoring. 